\title{
Is kinesiophobia a predictor of early functional performance after total hip replacement? A prospective prognostic cohort study
}

M. Morri ${ }^{1 *}$ (D), E. Venturini ${ }^{1}$, N. Franchini ${ }^{1}$, R. Ruisi ${ }^{1}$, A. Culcasi ${ }^{1}$, A. Ruggiero ${ }^{1}$, C. Govoni ${ }^{1}$ and M. G. Benedetti ${ }^{2}$

\begin{abstract}
Background: Considerable attention has been paid to the role of kinesiophobia with respect to knee prosthesis but it has not yet been studied as a prognostic factor of short-term functional performance following total hip replacement. The main purpose of the present study is to examine the possible predictors of early functional performance of patients undergoing total primary hip arthroplasty, including demographics as age, sex and body mass index, preoperative functional ability, type of anaesthesia, level of haemoglobin, pain and level of kinesiophobia before surgery. Secondly, we want to describe the main characteristics of the population with the highest levels of kinesiophobia.
\end{abstract}

Methods: A prospective, prognostic cohort study was carried out. Patients undergoing primary hip replacement were recruited consecutively. The main outcome is the early functional performance achieved by patients after surgery and measured using the lowa Level of Assistance (ILOA) scale on the fifth postoperative day. Preoperative kinesiophobia was measured by the Tampa Scale and the preoperative functional ability by the Western Ontario and McMaster Osteoarthritis Index (WOMAC). The multivariate analysis was performed by the General Linear Model. The analysis of the population with high levels of kinesiophobia was conducted by identifying a cut-off of 40 compared to the Tampa Scale.

Results: Statistical analysis was performed on 269 patients. The average ILOA score recorded was 19.5 (DS 8.3). The levels of kinesiophobia, showed an average score of 35.1 (7.8) and it was not associated with early functional performance. The independent predictive factors include age, sex and body mass index. Kinesiophobia high levels were recorded in 30\% of the population and this population had a higher level of pre-operative WOMAC score.

Conclusions: Early functional performance after hip replacement surgery was not correlated with the level of kinesiophobia. Three significant factors that describe a population most at risk of not achieving optimal functional performance are increased age, being female and increase in body mass index. In the preoperative phase, high levels of kinesiophobia were associated with more impaired preoperative functional ability.

Trial registration: Current Controlled Trials NCT02786121, May 2016. Retrospectively registered.

Keywords: Osteoarthritis, Arthroplasty, Psychology, Recovery of function

\footnotetext{
*Correspondence: mattia.morri@ior.it

${ }^{1}$ IRCCS Istituto Ortopedico Rizzoli, Servizio di Assistenza Infermieristico

Tecnico e Riabilitativo, Via Pupilli 1, 40136 Bologna, IT, Italy

Full list of author information is available at the end of the article
}

(c) The Author(s). 2020 Open Access This article is licensed under a Creative Commons Attribution 4.0 International License, which permits use, sharing, adaptation, distribution and reproduction in any medium or format, as long as you give appropriate credit to the original author(s) and the source, provide a link to the Creative Commons licence, and indicate if changes were made. The images or other third party material in this article are included in the article's Creative Commons. licence, unless indicated otherwise in a credit line to the material. If material is not included in the article's Creative Commons licence and your intended use is not permitted by statutory regulation or exceeds the permitted use, you will need to obtain permission directly from the copyright holder. To view a copy of this licence, visit http://creativecommons.org/licenses/by/4.0/ The Creative Commons Public Domain Dedication waiver (http://creativecommons.org/publicdomain/zero/1.0/) applies to the data made available in this article, unless otherwise stated in a credit line to the data. 


\section{Background}

Total hip replacement generally has a good level of success, usually guaranteeing complete restoration of joint function and elimination of painful symptoms $[1,2]$. However, in a percentage of patients, the risk of non-optimal functional recovery remains $[3,4]$. The planning of care pathways in today's orthopedic surgery units continuously require the need to combine the reduction in hospitalization time with early motor skills recovery. The possibility to identify patients at risk by determining the correct outcome predictors is a critical element in this context. Currently, factors that show to have significant roles in hip replacement surgery are age, sex, body mass index (BMI) and pre-operative functional level [5-9]. Interestingly, also high levels of kinesiophobia have been associated with worse outcomes in various diseases affecting the spine [10-12], upper limbs [13, 14] and lower limbs $[15,16]$. Kinesiophobia is defined as the fear and refusal of movement [17], based on the fear-avoidance model introduced by Vlaeyen et al. [18]. In patients undergoing knee replacement, authors showed a negative correlation between high levels of kinesiophobia and reduced knee flexion [19, 20], ambulatory performance [21, 22], pain $[20,22]$ and length of hospital stay [23]. In literature, Kinesiophobia was measured using the Tampa Scale and patients with high levels of Kinesiophobia were identified for scores greater than 40 [21].

Considerable attention has been paid to the role of kinesiophobia with respect to knee prosthesis, however, to our knowledge, it has not yet been studied as a prognostic factor of short-term functional performance following total hip replacement. Therefore, the main aim of the present study is to examine the possible predictors of early functional performance in terms of short-term autonomy of patients undergoing total primary hip arthroplasty, including demographics as age, sex and body mass index, preoperative functional ability, type of anaesthesia, level of haemoglobin, pain before and after surgery and level of kinesiophobia before surgery. Secondly, the study aimed to describe the main characteristics of the population with the highest levels of kinesiophobia and to analyze any differences with the population with lower levels of kinesiophobia.

\section{Methods}

\section{Study design}

Prospective-prognostic cohort study.

\section{Participants}

The present study was carried out at a single-specialized orthopedic hospital in a 33-bed surgical department for hip joint replacement. Patients undergoing primary hip replacement with a minimally invasive and lateral approach were recruited consecutively according to the following inclusion criteria: age range between 18 and 75 years old, symptoms of hip pain at least 3 months before surgery. A period of at least 3 months was deemed necessary for the onset of the mechanisms of fear the of movement, characteristic of kinesiophobia, which present an alteration of function from a clinical point of view [18]. Patients who underwent hip replacement due to trauma or surgical revision, other surgical treatments of lower limbs in the last year, with concomitant rheumatic diseases (rheumatoid arthritis, ankylosing spondylitis) and/or neurological diseases (Parkinson's disease, stroke) or with signs of cognitive impairment, were excluded from the study. In addition, patients were excluded from the study in cases where orthopedic complications of failed prosthetic implants (dislocations or implant mobilization) or major complications occurring during postoperative hospitalization causing interruptions in the normal rehabilitation process. The study received formal approval from the Institution's ethics committee and each patient provided written consent. The study was registered on the ClinicalTrials.gov registry (N. NCT02786121).

\section{Outcome measure}

The main outcome is the early level of functional performance achieved by patients measured using the Iowa Level of Assistance (ILOA) scale on the fifth postoperative day. The ILOA scale was studied and validated by Shields et al. [24] and has been used in several studies with populations similar to the present one $[6,25,26]$. The scale presents five items: sitting position, standing position, walking, stair climbing and walking speed. Each activity in the study is measured according to the degree of assistance requested and aid used. Assistance levels were evaluated with scores from 0 to 6 , where lower scores indicate greater functional independence. The scale for aids used are evaluated with scores from 0 to 5 . The total score ranges from 0 to a maximum of 50 . No specific cut-off was settled.

\section{Study variables}

The variables considered and subsequent samples collected were identified before the start of the study through literature research.

Demographics and clinical variables: age, gender, body mass index (BMI), type of anesthesia (total, spinal and combination), intensity of pain (Numerical Rating Scale - NRS) [27], hemoglobin variation (calculated as the difference between the preoperative value and the minimum value recorded in the first five postoperative days) and the onset of complications (urinary tract, respiratory tract, cardiovascular system and skin) were the variables of which samples were collected by a clinician and recorded. 
Self-reported measures: during preoperative admission at the hospital's orthopedic department, the physiotherapist recruited patients based on inclusion and exclusion criteria, collected study consent forms and administered the following assessment scales:

- the preoperative functional ability was measured by the Italian version of the Western Ontario and McMaster Osteoarthritis Index (WOMAC) [28]. This scale was developed for patients with osteoarthritis of the hip and knee and has been proven to be valid and repeatable [28]. The WOMAC consists of 24 items that are evaluated according to a 5-point Likert scale with scores from 0 to 4 for each item and divided into 3 groups: pain, stiffness and function. Higher scores indicate greater difficulty with an overall score that could range from 0 (no limitation) to 96 (maximum limitation).

- the level of kinesiophobia was measured using the Tampa Scale for Kinesiophobia (TSK). The Italian version [29] provides 13 items each of which uses a Likert 4-point scale that ranges from 1 (strongly disagree) to 4 (strongly agree). The total score is calculated by adding up the scores of each item, the higher scores representing higher levels of kinesiophobia. The total score ranges from 13 (absence of kinesiophobia) to 52 (maximum fear of movement). This variable was collected as a continuous variable for the main purpose of the study in the analysis of predictive factors relating to early functional performance. The evaluation of kinesiophobia was carried out on the preoperative day. In order to meet the second objective of the study and describe the main characteristics of the population with the highest kinesiophobia scores and any differences with the population with lower levels, based on some studies on knee prosthesis [20,21], a cut-off score of 40 was established. This secondary analysis had the role of providing possible indications for further studies and insights in relation to the role of Kinesiophobia in the processes that lead patients to hip replacement surgery.

\section{Inpatient physiotherapy program}

Physiotherapy during the postoperative phase required two daily 30-min sessions of physical therapy starting from the first postoperative day. The exercise program was carried out early on and accelerated with the aim to achieve upright position on day one, walking with a frame on day two, walking with forearm crutches on day three, and, depending on the patient's clinical conditions, ascending three steps. Each physiotherapist was free to choose the activities to execute in each session from the physiotherapy schemes. No specific assessment or physiotherapy treatment was planned out regarding patients who had significant anxiety levels. In cases where the physiotherapist considered it appropriate, it was possible to verticalize the patient in two operators to obtain a greater level of safety. The pharmacological treatment set in the postoperative phase did not provide the use of targeted therapy for anxiety, except in cases where treatment was not already being carried out in the patient on a regular basis during the preoperative period.

\section{Sample size}

The ILOA scale in a sample of 167 previously studied patients [6] at the same surgery department had an average score of 16.6 with standard deviation of 6.5 at hospital discharge. The number of patients enrolled in this study was sized on this score and on the number of predictive parameters included in the multivariate statistical analysis. Therefore, based on these considerations, it was estimated to enroll a sample of at least 200 subjects.

\section{Statistical analysis}

All continuous data are expressed in terms of mean \pm standard deviation (SD) and categorical variables are expressed as proportions or percentages. The Kolmogorov Smirnov test was performed to test normality of continuous variables. The Spearman's rank correlation was used to assess correlation between continuous data and the Pearson chi square test, evaluated by the exact method (to manage small subgroups), was performed to investigate the relationships between grouped variables. One-Way ANOVA was performed to assess differences among groups when the Levene test for homogeneity of variances was not significant $(p<0.05)$, alternatively the Mann Whitney test was used. The multivariate analysis was performed by the General Linear Model with the fixed effects as the categorical predictor, and the covariates as the continuous predictor. For all tests, $p<0.05$ was considered significant. Statistical Analysis was carried out by using the Statistical Package for the Social Sciences (SPSS) software version 15.0 (SPSS Inc., Chicago, USA). In addition to the main analysis described here, a further analysis was conducted to investigate possible differences between the basic characteristics of the sample in relation to high levels of Kinesiophobia, for Tampa Scale scores greater than 40 .

\section{Results}

A total of 284 patients were enrolled between May 2016 and February 2017, according to the inclusion criteria. The flow of patients and the reasons for exclusions are outlined in Fig. 1. Complications occurred in 12 patients (4.5\%). Statistical analysis was performed on 269 patients. The description of the sample and of the variables collected and used for statistical analysis is summarized in Table 1 for continuous variables, and in Table 2 for categorized variables. The average ILOA score was 19.5 (DS 8.3). 


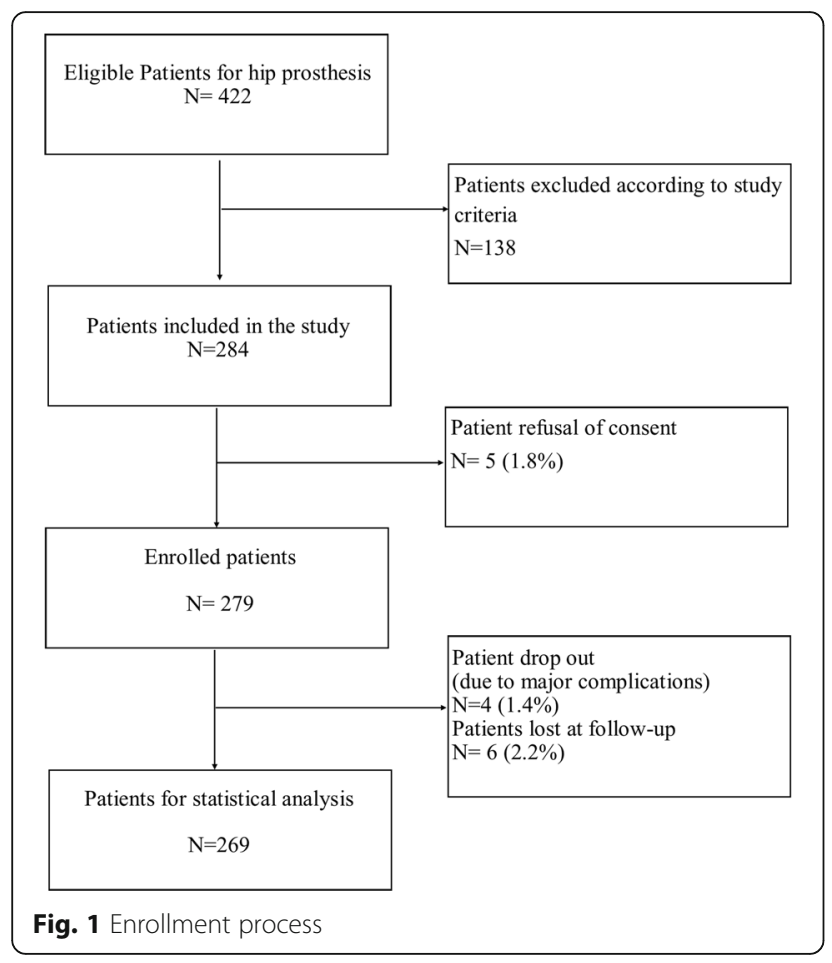

The level of kinesiophobia, measured by the Tampa scale, showed an average score of 35.1 (7.8). This variable was not associated with early functional performance measured by ILOA score. Instead, the univariate analysis showed increase in age, increase in body mass index and a more compromised functional preoperative status measured with WOMAC score, as risk factors. Results showed protective factors to be the male sex, a higher preoperative hemoglobin level and a greater reduction in hemoglobin in the postoperative phase.

Table 1 Characteristics of the population and univariate analysis between continuous variables and ILOA score

\begin{tabular}{llll}
\hline Variables & $\begin{array}{l}\text { Mean } \\
\text { (DS) }\end{array}$ & ILOA TOT & \\
\cline { 3 - 4 } & $59.9(10.5)$ & 0.263 & $<0.0005$ \\
\hline Age & $26.9(4.1)$ & 0.135 & 0.027 \\
BMI & $51.9(14.3)$ & 0.147 & 0.016 \\
WOMAC total & $9.5(3.4)$ & 0.057 & 0.351 \\
WOMAC pain & $4.7(1.7)$ & 0.092 & 0.134 \\
WOMAC stiffness & $37.9(10.1)$ & 0.149 & 0.015 \\
WOMAC function & $35.1(7.8)$ & $-0.360^{\mathrm{a}}$ & 0.556 \\
Pre TSK & $14.0(1.3)$ & -0.168 & 0.006 \\
Pre Hemoglobin & $4.1(1.4)$ & -0.134 & 0.028 \\
\hline Delta Hemoglobin & &
\end{tabular}

Missing cases: 3 for WOMAC; 6 for pre TSK; 1 for per Hemoglobin and 1 for Delta Hemoglobin

apearson correlation
Table 2 Characteristics of the population and univariate analysis between categorical variables and ILOA score

\begin{tabular}{llll}
\hline Variables & Frequency (\%) & ILOA Mean (DS) & $P$ value \\
\hline Sex & $118(43.9)$ & $17.1(7.5)$ & $<0.0005$ \\
$\quad$ Male & $151(56.1)$ & $21.6(8.4)$ & \\
$\quad$ Female & & & \\
Anesthesia & $26(9.7)$ & $21.9(9.6)$ & 0.276 \\
$\quad$ Total & $13(4.9)$ & $18.5(6.7)$ & \\
Spinal & $229(85.4)$ & $19.4(8.2)$ & \\
Combination & $243(90.7)$ & $19.4(8.2)$ & 0.458 \\
At least one day with pain > 3 (NRS) & & \\
No & $25(9.3)$ & $21.7(9.0)$ & \\
Yes &
\end{tabular}

Missing cases: 1 for anesthesia and 1 for pain

The significant variables were included in the multivariate analysis model and results are summarized in Table 3. The independent predictive factors include: age, sex and body mass index.

Further analysis was conducted on the characteristics of the sample and postoperative outcomes of patients with a high level of preoperative kinesiophobia. Patients with high preoperative kinesiophobia scores, greater than 40 , measured with the Tampa Scale, were $30 \%$. The results of this secondary analysis are shown in Table 4 . Patients with higher levels of kinesiophobia before surgery had higher WOMAC score. No further differences emerged between the population with higher and lower levels of kinesiophobia.

\section{Discussion}

In the present study, the increase in age, female sex and the increase in BMI emerged as independent predictors of the worse recovery of patient autonomy after total primary hip replacement; this association did not emerge with respect to kinesiophobia. The recovery of functional autonomy measured by the ILOA scale showed an average score of 19.5 (SD 8.3) on the fifth postoperative day. This value is in line with the average score of 18.2 (DS 7.7) reported by Stockton and Mersegne [26] in which the evaluation was carried out on the sixth postoperative day. Kinesiophobia was highlighted as a significant factor in various studies [19-23, 30], which showed a worse outcome compared to post-operative recovery.

Table 3 Multivariate analysis for ILOA

\begin{tabular}{lllll}
\hline Variables & B & \multicolumn{2}{l}{$\mathbf{9 5 \% \text { Wald confidence interval }}$} & \multirow{P}{P}{} \\
\cline { 3 - 4 } & & Lower limit & Upper limit & value \\
\hline Age & 0.172 & 0.83 & 0.261 & $<0.001$ \\
Male Sex & -4.435 & -6.321 & -2.55 & $<0.001$ \\
BMl & 0.279 & 0.048 & 0.509 & 0.018 \\
\hline
\end{tabular}


Table 4 Analysis for Kinesiophobia groups

\begin{tabular}{|c|c|c|c|}
\hline & $\begin{array}{l}\text { Kinesiophobia }<40 \\
N=187\end{array}$ & $\begin{array}{l}\text { Kinesiophobia } \geq 40 \\
N=82\end{array}$ & Pvalue \\
\hline \multicolumn{4}{|l|}{ Baseline Characteristic } \\
\hline Age, mean (DS) & $59.5(10.3)$ & $61.1(11.0)$ & 0.166 \\
\hline Female, \% & 44.9 & 41.5 & 0.689 \\
\hline BMI, mean (DS) & $27.0(4.2)$ & $27.2(4.0)$ & 0.711 \\
\hline Hemoglobin, mean (DS) & $13.9(1.3)$ & $14.0(1.4)$ & 0.592 \\
\hline Womac pain, mean (DS) & $9.3(3.3)$ & $10.0(3.6)$ & 0.079 \\
\hline Womac stiffness, mean (DS) & $4.6(1.6)$ & $4.7(1.9)$ & 0.428 \\
\hline Womac function mean (DS) & $36.8(10.1)$ & $39.9(9.7)$ & 0.011 \\
\hline Womac total, mean (DS) & $50.7(13.9)$ & $54.6(14.2)$ & 0.015 \\
\hline Pre TSK, mean (DS) & $31.4(5.6)$ & $44.1(3.3)$ & $<0.0005$ \\
\hline \multicolumn{4}{|l|}{ Postoperative outcome } \\
\hline Length of hospitalization (LOS) mean (DS) & $5.98(1.8)$ & $6.04(1.3)$ & 0.794 \\
\hline At least one day with pain $>3$ (NRS), $\%$ & 9.6 & 8.6 & 1.000 \\
\hline ILOA Score, mean (DS) & $20.0(8.9)$ & $18.8(6.9)$ & 0.332 \\
\hline
\end{tabular}

The mean Tampa scale score reported by DouryPanchout [21] was 36.5 (6.7), slightly higher than the score reported in the present study of 35.1 (7.8) in the preoperative phase. The population with high levels of kinesiophobia had an average score of 43.7 (3.5) and 46.0 (10.2), respectively, in the Doury-Panchout and Guney-Deniz studies, which is in line with the score of the present work of 44.1 (3.3). Moreover, the percentage of patients with a high level of kinesiophobia was 36 in the Doury-Panchout study, and 47.8 in the Guney-Deniz study, while in the present study it was 30 . Therefore, in patients who undergo knee replacement, kinesiophobia seems to have the same intensity as patients with osteoarthritis of the hip, but with a higher frequency. This aspect could also explain the difference in the role that this factor plays in the postoperative recovery phase. Fear of movement mechanisms likely to associate with post-operative recovery are probably more common in patients with knee replacement. An association between joint function and kinesiophobia level emerges in patients with hip replacement, who report that fear of movement seems to have a significant role in the process that leads to worsening of function but is not directly associated with preoperative pain symptoms.

It should be borne in mind that the above referenced studies were aimed at patients undergoing knee prosthesis and many of these cases presented an underestimated sample size with possible bias. In Archer et al. [31], in patients undergoing spinal surgery, it was confirmed, instead, that preoperative kinesiophobia was not correlated with functional outcomes evaluated at 6 weeks and 6 months after surgery, while there was an association between the same outcomes and postoperative kinesiophobia. It remains to be clarified what is the role of surgical intervention that modifies the structure of the hip joint and soft tissue in a very short time, with respect to kinesiophobia, which authors have described as a process of pathological adaptation with prolonged modes and timing. Further studies are needed to understand whether a preoperative condition of fear may be significantly correlated with longer-term outcomes. As previously mentioned, increase in age was found to be one of the factors associated with postoperative functional outcome. Indeed, several authors have shown this correlation [5, 6, 32], both with respect to a functional outcome and to the evaluation of the length of hospital stay [33]. In addition, sex emerged as another variable linked to patient characteristics associated with the ILOA score. In fact, women showed a lower level of recovery compared to men, as already highlighted in the studies of Vincent [5], Morri [6] and Elings [34]. In these studies, the age of the female population is slightly more advanced, additionally, their conditions of pain and preoperative function are worse than their male counterparts; these aspects could possibly explain the poorer results of post-operative recovery.

The only factor that emerged as significant, which was possible to intervene during the preoperative phase was BMI. In the literature however, the role of BMI has not yet been defined in a decisive manner. For example, in Vincent's study [5], BMI did not appear to be significant, while it was significant in the systematic reviews of Buirs [7], Liu [35], Elings [34] and Smith [32].

The preoperative functional ability was not associated with early postoperative recovery. In a literature review by Mak et al. [36], the authors showed how preoperative 
exercise was prescribed to maintain a better functional level and to reduce pain during the waiting period before surgery, but without associated it with post-operative recovery. On the contrary, Smith's study [32] and the systematic review of Buirs [7] showed association between preoperative functional ability and postoperative recovery. In addition, a higher hemoglobin level and greater blood loss emerged as protective factors with respect to the functional outcome. Ibrahim et al. [37] showed a correlation between the level of hemoglobin and the length of hospital stay. Therefore, in the present study, it can be hypothesized that hemoglobin played such a confounding role that the multivariate analysis lost significance, confirming the results of Schneider et al. [33].

\section{Limits}

The study presents some limitations. Among the preoperative variables, the comorbidities present were not evaluated. However, this factor does not significantly correlate with functional recovery reported in the literature [34]. Another limit is the length of follow-up. The study was aimed at early functional recovery, while a more prolonged follow-up over time may be useful in a further study to understand the role of kinesiophobia on outcomes in the medium to long term. Finally, the mean ILOA score (16.6 with SD 6.5) from which we started to calculate the sample size of 200 patients, was lower than the mean score that emerged from the study (19.5 with DS 8.3). The studied sample of 269 patients was, however more than originally expected and this allowed us to obtain stable results.

\section{Conclusion}

Based on our findings, early functional performance after hip replacement surgery was not correlated with the level of preoperative kinesiophobia. Three significant factors that describe a population more at risk of not achieving optimal functional performance are older age, female gender, and higher BMI. It is important to take these risk factors into consideration when planning both surgery and rehabilitation approach. In the preoperative phase, patients with high levels of kinesiophobia exhibit more impaired preoperative functional ability.

\section{Abbreviations}

BMI: Body Mass Index; ILOA: lowa Level of Assistance; NRS: Numerical Rating Scale; WOMAC: Western Ontario and McMaster Osteoarthritis Index (WOMAC); SPSS: Statistical Package for the Social Sciences

\section{Acknowledgements}

We would like to thank the ward of Orthopaedic-Traumatology and Prosthetic surgery and revisions of hip and knee implants" of the Instituto Ortopedico Rizzoli.

\section{Authors' contributions}

MM, study conception and design, analysed and interpreted the patient data, wrote the manuscript; EV, study conception, collected data and built data set, interpreted the data; NF, study conception, collected data and built data set; RR collected and interpreted the data; AC, study conception, collected data and built data set; AR, collected data and analysed and interpreted the patient data, MGB, analysed and interpreted the patient data, revised the paper critically for important intellectual content. All authors read and approved the final manuscript.

\section{Funding}

This work was supported by Nurse Research Center and Physical Medicine and Rehabilitation Department of Istituto Ortopedico Rizzoli, paying for the English translation. Not financial support was provided for the design of the study and collection, analysis and interpretation of data and in writing the manuscript.

\section{Availability of data and materials}

The datasets used and/or analysed during the current study are available from the corresponding author on reasonable request.

Ethics approval and consent to participate

All patients provided written informed consent before participating and the study protocol received formal approval from the Ethics Committee of Instituto Ortopedico Rizzoli. The study was registered on the ClinicalTrials.gov registry (N. NCT02786121)

\section{Consent for publication}

Not applicable.

\section{Competing interests}

The Authors declare that they have no competing interest

\section{Author details}

${ }^{1}$ IRCCS Istituto Ortopedico Rizzoli, Servizio di Assistenza Infermieristico Tecnico e Riabilitativo, Via Pupilli 1, 40136 Bologna, IT, Italy. ${ }^{2}$ RCCS Istituto Ortopedico Rizzoli, Servizio di Medicina Fisica e Riabilitativa, Bologna, Italy.

Received: 20 March 2020 Accepted: 28 October 2020

Published online: 07 November 2020

\section{References}

1. Marx RG, Jones EC, Atwan NC, Closkey RF, Salvati EA, Sculco TP. Measuring improvement following total hip and knee arthroplasty using patient-based measures of outcome. J Bone Joint Surg Am. 2005;87(9):1999-2005.

2. Bruyère $O$, Ethgen $O$, Neuprez $A$, Zégels $B$, Gillet $P$, Huskin JP, Reginster JY. Health-related quality of life after total knee or hip replacement for osteoarthritis: a 7-year prospective study. Arch Orthop Trauma Surg. 2012; 132(11):1583-7.

3. Judge A, Cooper C, Williams S, Dreinhoefer K, Dieppe P. Patient-reported outcomes one year after primary hip replacement in a European collaborative cohort. Arthritis Care Res. 2010;62(4):480-8.

4. Hawker GA, Badley EM, Borkhoff CM, Croxford R, Davis AM, Dunn S, Gignac MA, Jaglal SB, Kreder HJ, Sale JE. Which patients are most likely to benefit from total joint arthroplasty? Arthritis Rheum. 2013;65(5):1243-52.

5. Vincent HK, Alfano AP, Lee L, Vincent KR. Sex and age effects on outcomes of total hip arthroplasty after inpatient rehabilitation. Arch Phys Med Rehabil. 2006:87(4):461-7.

6. Morri M, Franchini N, Gerini G, Morabito R, Pignotti E, Benedetti MG, Marchese O, Zanotti E. Measuring functional performance at discharge from hospital after total joint arthroplasty as a pre-requisite for planning early rehabilitation: a prognostic study. Orthop Nurs. 2015;34(2):95-100.

7. Buirs LD, VanBeers LWAH, Scholtes VAB, et al. Predictors of physical functioning after total hip arthroplasty: a systematic review. BMJ Open. 2016;6:e010725. https://doi.org/10.1136/bmjopen-2015-010725.

8. Lungu E, Vendittoli PA, Desmeules F. Identification of patients with suboptimal results after hip arthroplasty: development of a preliminary prediction algorithm. BMC Musculoskelet Disord. 2015;16(1):279.

9. Oosting E, Hoogeboom TJ, Appelman-de Vries SA, Swets A, Dronkers JJ, van Meeteren NL. Preoperative prediction of inpatient recovery of function after total hip arthroplasty using performance-based tests: a prospective cohort study. Disabil Rehabil. 2016;38(13):1243-9. 
10. Landers MR, Creger RV, Baker CV, Stutelberg KS. The use of fear avoidance beliefs and nonorganic signs in predicting prolonged disability in patients with neck pain. Man Ther. 2008;13(3):239-48.

11. Mansfield M, Thacker M, Spahr N, Smith T. Factors associated with physical activity participation in adults with chronic cervical spine pain: a systematic review. Physiotherapy. 2018;104(1):54-60. https://doi.org/10.1016/j.physio. 2017.01.004

12. Nieto R, Miró J, Huguet A. Pain-related fear of movement and catastrophizing in whiplash-associated disorders. Rehabil Psychol. 2013;58(4): 361-8. https://doi.org/10.1037/a0034267.

13. Das De S, Vranceanu AM, Ring DC. Contribution of Kinesophobia and catastrophic thinking to upper-extremity-specific disability. J Bone Joint Surg Am. 2013;95:76-81.

14. Miedema HS, Feleus A, Bierma-Zeinstra SM, Hoekstra T, Burdorf A, Koes BW. Disability trajectories in patients with complaints of arm, neck, and shoulder (CANS) in primary care: prospective cohort study. Phys Ther. 2016;96(7):97284. https://doi.org/10.2522/ptj.20150226.

15. Helminen EE, Sinikallio SH, Valjakka AL, Väisänen-Rouvali RH, Arokoski JP. Determinants of pain and functioning in knee osteoarthritis: a one-year prospective study. Clin Rehabil. 2016;30(9):890-900.

16. Gunn AH, Schwartz TA, Arbeeva LS, et al. Fear of movement and associated factors among adults with symptomatic knee osteoarthritis. Arthritis Care Res. 2017;69(12):1826-33.

17. Knapik A, Saulicz E, Gnat R. Kinesiophobia - Introducing a New Diagnostic Tool. J of Hum Kinet. 2011;28(-1):25-31.

18. Vlaeyen JW, Linton SJ. Fear-avoidance and its consequences in chronic musculoskeletal pain: a state of the art. Pain. 2000;85(3):317-32.

19. Brown ML, Plate JF, Von Thaer $\mathrm{S}$, et al. Decreased range of motion following Total knee Arthroplasty is predicted by the Tampa scale of Kinesiophobia. J Arthroplast. 2016;31(4):793-7.

20. Güney-Deniz H, Irem Kınıklı G, Çağlar Ö, Atilla B, Yüksel İ. Does kinesiophobia affect the early functional outcomes following total knee arthroplasty? Physiother Theory Pract. 2017;33(6):448-53.

21. Doury-Panchout F, Metivier JC, Fouquet B. Kinesiophobia negatively influences recovery of joint function following total knee arthroplasty. Eur J Phys Rehabil Med. 2015;51(2):155-61.

22. Sullivan M, Tanzer M, Reardon G, Amirault D, Dunbar M, Stanish W. The role of presurgical expectancies in predicting pain and function one year following total knee arthroplasty. Pain. 2011;152(10):2287-93.

23. Witvrouw E, Pattyn E, Almqvist KF, et al. Catastrophic thinking about pain as a predictor of length of hospital stay after total knee arthroplasty: a prospective study. Knee Surg Sports Traumatol Arthrosc. 2009;17(10):1189-94.

24. Shields RK, Enloe LJ, Evans RE, Smith KB, Steckel SD. Reliability, validity, and responsiveness of functional tests in patients with total joint replacement. Phys Ther. 1995;75(3):169-76.

25. Lawlor M, Humphreys P, Morrow E, Ogonda L, Bennet D, Elliot D, Beverland D. Comparison of early postoperative functional levels following total hip replacement using minimally invasive versus standard incisions. A prospective randomized blinded trial. Clin Rehabil. 2005;19:465-74.

26. Stockton KA. Mengersen. Effect of multiple physiotherapy sessions on functional outcomes in the initial postoperative period after primary total hip replacement: a randomized controlled trial. Arch Phys Med Rehabil. 2009;90(10):1652-7.

27. Williamson A, Hoggart B. Pain: a review of three commonly used pain rating scales. J Clin Nurs. 2005;14(7):798-804

28. Salaffi F, Leardini G, Canesi B, Mannoni A, Fioravanti A, Caporali R, Lapadula G, Punzi L. Western Ontario and McMaster universities (WOMAC) OsteoarthritisIndex in Italian patients with osteoarthritis of the knee. Osteoarthr Cartil. 2003;11(8):551-60.

29. Monticone M, Giorgi I, Baiardi P, et al. Development of the Italian version of the Tampa scale of Kinesiophobia (TSK-I): cross-cultural adaptation, factor analysis, reliability, and validity. Spine. 2010;35:1241-6. https://doi.org/10. 1097/BRS.0b013e3181bfcbf6.

30. Filardo G, Merli G, Roffi A, Marcacci T, Berti CF, Raboni D, Bortolotti B, Kon E, Marcacci M M. Kinesiophobia and depression affect total knee arthroplastyoutcome in a multivariate analysis of psychological and physical factors on 200 patients. Knee Surg Sports Traumatol Arthrosc. 2016;24(10):3322-8.

31. Archer KR, Seebach CL, Mathis SL, Riley LH 3rd, Wegener ST. Early postoperative fear of movement predicts pain, disability, and physical health six months after spinal surgery for degenerative conditions. Spine J. 2014;14(5):759-67.
32. Smith GH, Johnson S, Ballantyne JA, Dunstan E, Brenkel IJ. Predictors of excellent early outcome after total hip arthroplasty. J Orthop Surg Res. 2012; 25(7):13.

33. Schneider M, Kawahara I, Ballantyne G, McAuley C, Macgregor K, Garvie R, McKenzie A, Macdonald D, Breusch SJ. Predictive factors influencing fast track rehabilitation following primary total hip and knee arthroplasty. Arch Orthop Trauma Surg. 2009;129(12):1585-91.

34. Elings J, Hoogeboom TJ, van der Sluis G, van Meeteren NLU. What preoperative patient-related factors predict inpatient recovery of physical functioning and length of stay after total hip arthroplasty? A systematic review. Clin Rehabil. 2015;29(5):477-92.

35. Liu W, Wahafu T, Cheng M, Cheng T, Zhang Y, Zhang $X$. The influence of obesity on primary total hip arthroplasty outcomes: a meta-analysis of prospective cohort studies. Orthop Traumatol Surg Res. 2015;101(3):289-96.

36. Mak JC, Fransen M, Jennings M, March L, Mittal R. Harris IA; National Health and Medical Research Council (NHMRC) of Australia. Evidence-based review for patients undergoing elective hip and knee replacement. ANZ J Surg. 2014;84(1-2):17-24.

37. Ibrahim MS, Twaij H, Giebaly DE, Nizam I, Haddad FS. Enhanced recovery in total hip replacement: a clinical review. Bone Joint J. 2013;95-B(12):1587-94.

\section{Publisher's Note}

Springer Nature remains neutral with regard to jurisdictional claims in published maps and institutional affiliations.
Ready to submit your research? Choose BMC and benefit from:

- fast, convenient online submission

- thorough peer review by experienced researchers in your field

- rapid publication on acceptance

- support for research data, including large and complex data types

- gold Open Access which fosters wider collaboration and increased citations

- maximum visibility for your research: over $100 \mathrm{M}$ website views per year

At BMC, research is always in progress.

Learn more biomedcentral.com/submissions 